\title{
FORGING A NEW PARADIGM: ON THE STRUCTURE OF THE INTERDISCIPLINARY AND ITS APPLICATION
}

\author{
Dr. Daniel Shorkend ${ }^{1 *}$ \\ ${ }^{* 1}$ Technion Institute of Technology, Haifa, Israel
}

*Corresponding Author: -

\begin{abstract}
: -
This article has three sections. In section one, I define my terms which leads to an outline of what this New Paradigm is. In section two, I develop this paradigm and suggest a visualization of it, a structure as it were. This will assist in a more thorough understanding of such a paradigm. Theoretical speculations and modelling aside or rather avoiding a purely" philosophical bias, I then apply this model to an example culled from art and aesthetics, yet involving, in line with this New Paradigm, other disciplines such as science and sport in order to exemplify or perhaps prove my argument, by virtue of the "mixture" or inter-disciplinary framework as applied to several different variables. This section forms the bulk of the article as such an application concretizes the theoretical framework in specific ways so that the reader will ascertain the usefulness of such a venture, which in turn ought to spur and spawn future research.
\end{abstract}

Keywords: - Art; Science; Expressionism; Aesthetics; new paradigm 


\section{INTRODUCTION:}

This article has three sections. In section one, I define my terms which leads to an outline of what this New Paradigm is. In section two, I develop this paradigm and suggest a visualization of it, a structure as it were. This will assist in a more thorough understanding of such a paradigm. Theoretical speculations and modelling aside or rather avoiding a "purely" philosophical bias, I then apply this model to an example culled from art and aesthetics, yet involving, in line with this New Paradigm, other disciplines such as science and sport in order to exemplify or perhaps prove my argument, by virtue of the "mixture" or inter-disciplinary framework as applied to several different variables. This section forms the bulk of the article as such an application concretizes the theoretical framework in specific ways so that the reader will ascertain the usefulness of such a venture, which in turn ought to spur and spawn future research.

\section{I. "Sketching" the framework:}

The New Paradigm I will argue for is the necessary interrelatedness of knowledge and experience, which at the same time elides an absolute description of reality. This is not simply a case of the limitations of our knowledge and experience or one's partial grasp of reality, but that the very fact that, to borrow a metaphor ${ }^{1}$ from physics, light behaves not simply as a particle, a discrete something, but also flows and vibrates as a wave; it is, as it were spread out and imprecise. It is this nature of nature that precludes a total grasp or elides definitive analysis and understanding. Yet one may experience this interrelatedness or oneness, in the same way our senses cojoin in say the experience of eating a meal, even if one sense (or discipline within the field of knowledge) may be dominant at any one time.

The central argument of this article on which such a paradigm hinges is that the various branches of what is aptly called the "body of knowledge" - and notwithstanding the evolution and development of this organism, if you will - is that each such discipline is both independent and inter-dependent.

Insofar as each such branch is independent, each discipline is marked by its own internal coherence or form. It exists as a seemingly self-sufficient, robust system and can be understood in its own terms. In this sense it constitutes a language. Now, a language has a syntax and semantics and can be learnt, developed and operates as a system of signification. It is based upon rules; its own internal logic (which could be otherwise) and forms a cultural game, that is to say one may apply Wittgenstein's notion here, namely that it is integral to a "form of life" and that its meaning is in its use.

Insofar as each such branch is inter-dependent, one cannot simply understand the form (of knowledge, of a language...) without reference to something else, whether it is a world; another language; other disciplines or branches of knowledge; other systems of knowing and acting in the context of a certain "form of life". A game is only a game, insofar as there is that which is not a game. Ideas, definitions and so on are therefore necessarily inter-dependent in order for there to be a system of signification, even in the instance of one dealing with polar, dualistic oppositions.

Let me make both notions of independence and inter-dependence less abstract and provide a few examples to strengthen this point: One can "do" history of art or say, pure mathematics without reference to anything outside the system. In the former case, I might analyze the formal changes and shifts in style over a period of time and discern the development of such styles within a given period. I may attribute a certain meaning to these shifts in technique and thus establish a picture of stylistic innovations over time and place, depending on the focus of such a study. In the latter case, I can multiply an unknown variable with the same variable and add the exponents without any reference to what these equations or sums so refer; it is simply a formal game that follows its own inherent logic or grammar.

One can take any discipline and follow the same reasoning - one simply follows the dictates of its own principles and "does it" accordingly, without any such connecting to other domains. History is history. Politics is politics. Biology is biology. And so on. Its meaning is not simply tautological or redundant or simply a formal game bereft of meaning, for within its own ambit of principles, axioms and analysis, one accrues knowledge within that domain and so progress is made. Indeed, in simpler terms: a cricket game, say a test match is self-enclosed game over 5 days that may be experienced on its own merit - and perhaps in relating to the history of cricket, certainly its rules - without any care or reference to anything beyond or outside those perhaps glorious five days, if one were so inclined.

Yet, there is another way to see knowledge and experience; one which recognizes the necessary unity and inter-relatedness of knowledge, of things. It would appear perhaps more "messy"; on the other hand, it can also yield knowledge and is necessarily a part of each such game, system, language or branch of knowledge at the same time.

If one piers into the "story of art" (to borrow from Gombrich), then one will notice that the unfolding of such a story is not simply a tour de 'force of stylistic and formal innovations and developments, an arts-for-arts' sake formalist account, but the mixture of "other" information, such as the artist's psychology; the historical period of time in terms of its politics, economics, religious outlook, philosophy and so on and so forth in a "dance" that then confers meaning on the art-object

\footnotetext{
${ }^{1}$ Metaphor is a useful concept in the context of this article. Rather than our ability to say what $\mathrm{x} i s$, what reality really is, and pinpoint a discrete particle with definite properties, the very fluid nature of reality, its wave-function precludes exact description (and knowledge). At best, then one can say what something is like or akin to or approximates - and metaphorical description is the very mechanism by which one can do so. It also allows the borrowing on one system/language/discipline and applying that in another domain or branch of knowledge which is "exactly" what I so conjecture and argue for.

2 The idea of the "other" as in the "other" of language or that which is beyond the interdependent terms of the text in the Derridean sense, substantiates my argument, wherein, on the one hand language acts as a closed field, and yet on the other, admits an "other", an "other of...", a reference if you like. The "language turn" is the equivalent in philosophy of my contention that all branches of knowledge are inter-dependent while reality itself cannot be accurately known (the old epistemological conundrum). The New Paradigm then, in a sense may be subverted, in that
} 
and the personality of the artist. That is to say, aesthetic and extra-aesthetic descriptions apply, neither cancelling the other, yet neither description sufficient in nor of itself. Similarly, mathematics does not simply "stand alone" as pure logic or a formal game but is enmeshed in physics and other sciences; follows a history that in turn is co-joined with a very human world, a social order of sorts from whence the fruits of mathematics were born, and it may be argued is relativized according, within a milieu and certain social and cultural conventions and so on. Such an acknowledgement which I have but briefly outlined can and does factor into to all disciplines within the ambit of knowledge and knowledge claim, now one discipline dominant, now another, yet all-inclusive of the "other", just as one cannot get a foreground without the concomitant background, as it were.

\section{Visualizing the structure of the interdisciplinary New Paradigm: II a) Theoretical formulation}

What I am proposing is not another discipline (that would just beget yet another and so on and so forth), but rather a theoretical framework in which all disciplines form a coherent unity, even as they develop within themselves and in relation or as overlapping with other disciplines, far and wide, deep and superficial. This then is not a "Theory of Everything" (so named T.O.E. in physics) lodged within a particular discipline for such an explanation is still within the formal language or form of that discipline and therefore even though in a reductive manner it may claim supremacy as the basis for all others - in the sense that one might argue that physics leads to chemistry which in turn leads to the life sciences and then at the other end of the spectrum moves towards the humanities - it is expressed and understood within and as physics and therefore cannot contain a world-picture. It is a separate discipline, even as it may act as a back-bone for all the others.

Thus, what I am describing is merely like a set that is not a set. The interdisciplinary New Paradigm - the phrase itself implying a distinct and limited entity - is itself not subject to any other set language/form/discipline. It is rather an idea that supervenes within and above the manifestation of knowledge under any one or several or connected branches (of knowledge). It is "new" in the sense that it offers the possibility of oneness and unity, rather than divide, separation, and specialization.

It is holistic, rather than analytical; it is applicable to all domains while itself not being a domain. Yet for all its esoteric non-specificity and definition, it has pragmatic value and a contribution to offer. It not so much fills a gap but creates a gap. In metaphorical terms all systems/ languages/ forms/ branches of knowledge are then contained therein, which itself allows the very enmeshing of such forms to take place. Yet it is not just a "messy muck" but has both analytical and specialist attributes. With such a concept, one can do research that is indeed interdisciplinary and allows anything to be matched and compared drawing likenesses and connections between seemingly separate research fields. In this way, both new knowledge emerges as well as a deeper appreciation for unity, rather than, or perhaps amidst apparent fragmentation. I am not simply giving another "Kantian" predisposition, an inherent axiomatic structure of the mind or brain; rather I humbly claim that the Interdisciplinary New Paradigm is even more foundational. It is the need to unify. The need to see the big picture. A vision, perhaps of infinity or at least the unity of separate entities, like an abstract device such as a number that enables things to be counted or related. Or like the fusion made by Einstein that links - against the prevailing traditions - both the concept of time and space.

\section{II b) Diagrammatic explanation:}

Consider a single discipline. We can represent that as a point. "Within" this point are all the details of that discipline. It is sub-divided in several ways as the discipline grows and evolves and develops.

In order for it to be, it has to be defined in relation to something else (another discipline), that is to say $\mathrm{A}$ is $\mathrm{A}$ and $\mathrm{A}$ is not not A, or B. Once there are two such imaginary "points", then there is the basis for our conceptual line. For there to be a

line or extension, there must be the concept of space, two dimensions. In this sense, though the points are initially defined as distinct, they are related. They form a line. A line in space. The line can be considered horizontal, the points are of equal value in plane. Or they can be drawn vertical, in which case one is said to be foundational and the other a result of the first. In this sense, space implicates time, a "before" and "after", for to speak of change and development and relationships, is to speak of a sequence and process; matter, space, and time are in motion. One might call it the relationship, dialectic, or oscillation between a positive and negative charge, to draw an analogy or metaphor culled from say physics or chemistry. Since there is some notion, the imaginary line itself is not simply either horizontal or vertical but may bend and contort and flow in various ways. One might summon the image of a Pollock "drip painting" to visualize such a dynamic. Such an image follows our simple line of two points that begets enumerable more such points and thence lines and so a complex interaction can assume form within the plane (or canvas surface - to continue the metaphor). Yet there are many "steps" before a complex web of seeming chaos. A line leads to 3 points, a triangle; four point implicates the square, and this iteration continues so that one gets the basic Platonic -like shapes. Then, a third dimension is added so that there is not simply height and width, but also volume or three dimensions. The form it takes can be visualized as chemical bonding and crystalline structures, yet this is so only by way of analogy. The exercise of which I am describing refers to a conceptual realm that can be applied across and between and within disciplines, that is to say, the organic body of knowledge, if you will.

there is no ultimate paradigm (no dominant field of knowledge, language, form...), only a shifting "wave", an indescribable reality that one might metaphorically allude to or hint at, and pragmatically manipulate, while the source of qualia is unknown. Kant then made a brilliant distinction between the noumena and the phenomena. 
Returning to the initial point, one might also envisage a particular discipline as a circle in which are contained further details (circles) and that once again, it is, because it is not something else (another discipline). Paradoxically, in that separation, they are connected, that is to say, the circles overlap (or bond). In this hypothetical image, a line barely exists for constituted by circles or points, it is but a useful fiction or mode. The image approximates, just as the visual sense of seeing is a partial description of a thing and requires the other senses as well as the assimilation of qualia in terms of rational systems of thought: categorizing; naming; counting and understanding processes and so on.

To render this less abstract, I can draw from exemplar cases in various domains or disciplines: In physics, one might say particles are "pulled together" via the strong force; in cosmological terms masses are attracted via gravity; in chemistry, the charges create bonded structures; in the life sciences, organic bodies "eat", "replicate", dispose of waste and so on and in the humanities one can speak of the overlap of say art and history, which one might then call "the history of art" and so on.

The upshot of all this is the inter-relatedness of all such branches of knowledge. The humanities and the sciences as the apparent furthest ends of the spectrum or line or form or body of knowledge, are connected insofar as science is necessarily human science, not so much that reality "in itself", but our mediation structures ${ }^{3}$, namely our means of understanding it (reality), limited by our senses, categories of thought or methods and perhaps, whether the cup of coffee this morning has rendered me alert enough to pen this down.

With these images and abstractions in mind, I will now develop a practical example of how this interdisciplinary nexus can be applied. This will substantiate my argument and convey one way wherein aesthetics; art history; science and sport - apparently disparate and unrelated fields (points or circles) - might be connected. If this is sound, then indeed one can see the explanatory and pragmatic power of the idea that I propose. Admittedly, even if valid, this is but one example and "purists" may dissent and argue for the formal coherence and separation of fields of knowledge; that this isolated example is random, a chance event - and that in the main, one cannot confuse A and B. Fiction is fiction. Nonfiction is non-fiction. My idea (somewhat) equates fiction and non-fiction and that sounds non-sensical. Yet, on close inspection it is not. As the poet is wont to say, reality is a dream. And the physicist might quip, some particles appear to not exist and do not even possess mass.

\section{One possible application: "Mixing" art, aesthetics, science and sport: III a) Two surface observations (empirical evidence):}

One well-known explanation of the nature of art is the expressive theory in art and in line with what its' name denotes, conveys the idea that the essence of art lies in its expressive value, for practitioner and viewer alike. Moreover, one may apply such a notion to the participation in - and consuming of - sport $^{4}$. This section proposes two observations, and a certain confluence. In the process, one may reclaim the expressive theory as explanatory of both art and sport in some measure without grand claims that the individual and the body of work expresses "truth" as such. Similarly, one can extend the initial comparison of art with sport through the aesthetic theory of expressionism and extend such a comparison to that of science. My method for doing so is to asset the formulae sport (read: science), which is akin a mathematical substation, wherein "sport" may be replaced by "science". Other expressions include sportsperson (read: scientist) and art (read: science), sportsman (artist, scientist...), games (read: sciences, form (read: separation)) and sport (art. science...) with the same function. Without changes to the sense of the logic, in fact inviting a solution to ill-defined or undefined variables in the process, such an equivocation suggests or argues for an inter-disciplinary "mixing", though since there are innumerable other variables which might also be brought into the "mix", or equation, one cannot claim ultimate truth in such an exploration. But as the part mirrors the whole, so such an application of my newfound paradigm hints at such a truth and one possible structure it may so assume.

\section{Observation 1:}

An expression above language and towards the ineffable:

Physical activity and picture-making is crucial to our evolution; they need their primitive roots. Such activity, in both artmaking and sport (read: science) are also trans-rational and thus beyond the analytical mind. Furthermore, both are perfected through training, and require the special inner drive and intuition. The upshot of all this is that the artist (read: scientist) and sportsperson (read: scientist) allows us to extend the range of our expressive powers beyond that which we find within our own resources. For example, one may say that a Rothko or Bannister's running or a scientist solving an equation helps me to express a feeling which defies description.

One may attribute to such performances a kind of somberness, serenity, even the mystical. It is, perhaps as Kandinsky (in Jansen 1967:115) says: “...painting (sport...science)...needs its materiality for that very dematerialization that shows the road from the external to the internal" (brackets my inclusion). Via the "external" of say, a Newman painting, the onlooker may become aware of his own body. It is therefore no surprise that Newman asked his viewers to see his paintings closeup

\footnotetext{
${ }^{3}$ It is useful at this juncture to make the distinction between "lights" (light) and "vessels" (matter). The light is the "in itself", the point of origin, while the "vessel" is our mode of apprehending it or categorizing it in some or other way or form or language or discipline. The point is that the New Paradigm of the interdisciplinary suggests that the light is one and infinite, while the vessels are of perhaps finite measure. Since the vessel "houses" the light, each vessel (discipline) still is essentially that light, though as distinct forms, may appear different. Our lens is limited, while the light is not. Yet such a distinction is necessary for the purposes of definition. Essentially what my argument points to is the dissolution of the vessel/s and the perception of light. Of course, this is an impossibility and simply a logical and imaginary hypothesis. ${ }^{4}$ C,f, Shorkend, D. A New Interpretation of Sport derived from art-related Aesthetics, UNISA: South Africa.
} 
wherein a sense of the aliveness of the onlooker was conjured, a sense of place and awareness as opposed to separation. The visual experience may be said to be permeated with emotion. I would claim that to follow sports events on television does a similar thing to the onlooker (or be engaged in the learning the craft of scientific investigation and theoretical argument). The "external" close-up of the action vitalizes the viewer. In this close-up, we may experience a kind of nonverbal identification with the "external" that borders on the ineffable.

As for the practitioner of art and sport (read: science), one may surmise that in striving he or she can experience wholeness. By expressing themselves, they "press" themselves out. This "pressing themselves out" is like love and friendship which is both predicated on a lack and a giving of self. Similar perhaps to a Tolstoian desire to communicate and share, the practitioner is in a position to express "... a gift of the abundance of what we all are" (Hyland 1990:141). This is expressed in the non-verbal language of art and sport (read: science) $)^{5}$.

The language of the sporting event or artwork may have the veneer of linear time and logic, but in reality, given their primitive origins ${ }^{6}$, they are both expressions of an intense unnamed emotional need that defies verbal articulation. Metaphorically, we can say it is like that ballet move or that sound without being able to pinpoint exactly what that movement or that sound expresses (or is). In order to perform at a high level, one has to become one with the game or one with the act of painting or be in that ballet movement or in that sound, just flowing with it with full concentration. To the extent that one can do that, the sportsperson may say "the game played 221 me" or the painting told me what it wanted or that a scientific insight was revealed. This attitude transcends competitiveness. Bannister, the famous sub four-minute miler expressed a great sense of thankfulness at fulfilling his aims, rather than a sense of vanquishing his opponent. In sport (read: science) as in art, one is ultimately against oneself. This means that both sport (read: science) and art require introspection and incessant refinement to find and express that spark within.

That "spark" is not easy to define - one may be able to express it in the repetition of the same great play and by forging a style. One has thus said it non-verbally and beyond conventional language. Keenen (in Osterhoudt 1973 argues that sport is like theatre, in that it consists in performances within a special and contrived world, as "an idealization of the everyday" (one may make the same observation concerning scientific exploration). Like dramatic tragedy it has its "acts", for example, half time; "players" refer both to sportsmen and women and actors and actresses; there is clapping for a good performance and a quest for the great struggle. Camus (1913-1960) in Osterhoudt (1973:306) says: “...even today, the stadium crammed full of spectators for a Sunday match and the theatre which I loved with unequal intensity are the only places in the world where I felt innocent".

I believe that this "innocence" felt by Camus can be located in the primordial child-like quality to find meaning in games, the spirit demonstrated by the "players" and the inexpressible somehow represented to the senses as an aesthetic experience. Womack (2003) concurs that the arts and sport (read: science) are mediums of expression without recourse to words when she says, "sport communicates through the language of symbols and, like art, it dramatizes complex ideas that cannot readily be expressed in words" (Womack 2003:27).

In this light, one can make the brief argument that Yves Klein (1930-1965), an artist and expert judoka, sought an overlap of his love for art and understanding of the art and science of judo. He sought to express that which is above words in his performances. For example, in his paintings. Klein's blue monochromes were his language that creates a sense of weightlessness, the essence of a correct judo technique and spatial determinacy. The viewer may feel drawn into the depth of blue that appeared to transmute the material substance of the painting support into an incorporeal quality, tranquil and serene (adapted from Weitmeier 1995:19). I cannot say it better than Yves Klein himself: "What is blue? Blue is the invisible becoming visible ... blue has no dimensions. It is beyond the dimensions of which other colors partake" (in Weitmeier 1995:19). I believe it was this same ineffable search that he sought in art and through judo-movements, that the latter could also suggest a boundless sensibility, that which "has no dimensions" (is this not the scientific quest for understanding nature?),

While I have been describing how an art-like perception may apply to sport (read: science), paradoxically art, sport and science appear to "refer" to that which defies expression. Nevertheless, it is hoped that both can be experienced aesthetically and that they do bear some similarities in these respects. Of course, that acknowledgement cannot be mandated; it is but an argument. In this respect, the idea as to what constitutes the (a) aesthetic is a healthy debate.

\section{Observation 2:}

\section{The integration of mind-and-body}

I have been arguing that emotions and the expression thereof play a pivotal role in both art and sport (read: science) insofar as they are non-verbal and "point" to the ineffable. Now if emotions can be construed as the link between the bodily and mental, then an expressive theory of both art and sport (read: science) could account for a meaningful interweaving of mind-and-body through such endeavors. The benefit of such an "interweaving" is that art and sport (read: science) galvanize people in meaningful ways. Weiss (1969:39, brackets my inclusion) puts it like this: “...because art and sport (read: science) involve a controlled expression of emotions, making it possible for minds and bodies to be harmonized clearly and intensely, they offer excellent agencies for unifying men".

Shusterman's somaesthetics, rationalized with recourse to significant philosophers' points to the unity of mind-and-body and the interrelation between sensory experience, feelings and cognition, often using the phrase body-mind or mind-body.

\footnotetext{
${ }^{5}$ One would describe science as non-verbal. because its prime language is that of mathematics.

${ }^{6}$ The essence or source of science is as old as the desire to run and compete, that is to say sport; as old the impulse to paint of a wall or to carve and is not simply expressed around the $16^{\text {th }}$ century in Europe in the modern form (read: separation) of our science today.
} 
The individual too may benefit from this mind-body relationship. Weiss (1969:54) once more says: “...only he who expresses his emotions through such a possessed and structured body can become well-unified and not be undone by what he feels". In this process, the artist and sportsperson (read: scientist) is said to have a mind to quicken and guide his body and a body as a source for acts desirable and effective. It is a body used, not simply worked on by what is external to it. Weiss thus uses the analogy of not hand-in-glove to represent the nature of the mind and body and its apparent dualism, a perennial problem in philosophy. Rather the mind-body interaction is like fingers to a hand - the fingers or body presuppose a hand or mind. Through practice both tend towards a rule-governed, well-controlled action. It is in this action that we can grasp a sense of unity and integration of the self.

To unpack this further, we may say that there is a similar process and language at work in both art and sport (read: science). There is first a desire, then more clarified intentions, followed by "performance" which contribute to the realization of a prospect and finally commitment to continue performing in a certain way. This requires focus. I tend towards a phenomenological position which describes the unity of mental and physical activity as a kind of "lived body" in opposition to dualism. According to the phenomenological position, expression itself is considered a unified whole and an "integration" mentioned above. I would argue that science too resolves into various acts or activities that may be described in similar terms. Hyland (1990:102) puts it in these terms: “... an amalgam of man's incarnation reveals that man is an opaque and partially concealed being subject without clear and precise points of demarcation for the various aspects of his being; he is a unity of physical, background and psychological relationships necessarily interrelated and only meaningfully investigated when analyzed as a whole. This "unity" means that I do not simply have a body, but, in some sense, I am my body, and in sharper terms: mind, senses and use of the body cannot be isolated and mechanically described, all act in unison which is an expression of the "I"." Furthermore, in the same way that the artist forms a style and his individuality vitalized by artistic feeling and training in his craft, so too is the sportsman inspired by feeling and training in his craft. The net result of this may be perceived as "... a reunification of spiritual and corporeal faculties, that can be achieved only by an assiduous training in movement in time and space, and a diligent cultivation of a muscular strength" (Osterhoudt 1973: 42). This point applies equally well to the both the sciences and the arts because movement too is a basis for the arts and the craft of scientific experiment. One needs to train our motor-tactile faculties, and expression is a succession of movements.

Even where the art (read: science) is more conceptual and abstract as in the case of music or chemistry, there is an imaginative construction of movement as the music has a rhythm which could be applied to a dance routine, and its "playing" certainly requires a certain dexterity and the like, and the "work in the lab" can be construed as a kind of dance. In recognizing the indissoluble link between the mind-and-body in sport and art and science, one can say these activities have the potential to express a unity of self. This "unity of self" exists because the aesthetic can be embodied, that is, expressed. If sport (read: science), drawing from artistic expressive theories, can be understood as expressive, then it is likely that we would be able to find "moments" in traditional aesthetics where there is a shift for considering "other" activities as aesthetically expressive. In modifying Guyer's text somewhat, I believe this shift is forthcoming, no less from the philosophy of Kant.

\section{III b) An extension of sport aesthetics by applying Guyer's “Kant and the philosophy of Architecture”}

In this section I apply a reading of Guyer on Kant in which he argues that Kantian aesthetics and metaphysics may be read to argue that sport (read: science) is concerned with the expression of aesthetic ideas. In this sense, sport (read: science) is not just formal aesthetic "play', but grounded in extraaesthetic meaning-making comparable to the arts. The argument is based on the fact that Kant shifted his attention away from the arts as simply about disinterested formal harmony that tends towards the "mere" practical and beautifying logic in architecture, but that the latter is concerned with the expression of ideas.

The very fact that this may be applied to architecture - a practical art - may lead to the argument that other aesthetic and perhaps more practical domains like sport (read: science) can be similarly described. Kant did not write much about architecture in his aesthetic deliberations and has had little influence in the theory of architecture. Nevertheless, Guyer (2011) argues that given the indisputable influence of Kant's aesthetics on German Idealism in particular after the 1790 Critique of Judgement, it seems natural to look for the shift in philosophical thinking about architecture within Kant's aesthetics.

This shift explains Guyer (2012:15) is from a Vitruvian conception of architecture, where the main goals of architecture are utility and beauty, to a cognitivist or expressivist conception of architecture. The expressivist is here understood as, like other forms of art, as communicating abstract ideas, not just aiming for beauty and utility. This shift can be seen in Kant's thesis that all art involves the expression of "aesthetic ideas", that is the expression of rational ideas in a form that yields inexhaustible material for the play of the imagination. Guyer further maintains that given Kant's "loose specification" of just what sort of intellectual content aesthetic ideas have, means that it could express 1) its own function, 2) nature of its structure, 3 ) the physical forces that underlie the structure and 4) metaphysical ideas (adapted from Guyer 2011: 5-12).

In this regard, form is merely a springboard to that which is not-form, that is, meaning-making. The very fact that Guyer has applied Kant's aesthetics to the realm of architecture, usually considered an applied art and not (purely) art as such, perhaps invites an even more radical shift of Kant's thought to other domains. In light of the proposition that art and sport (read: science) share an aesthetic dimension, applying Kant's thoughts on "aesthetic ideas" to that of sport (read: science), is not far fetched. Sport expresses, albeit covertly in many cases: functionality (1), structure (2), physics (3) and even “deep" content (4). Sport's (read: science's) movement is functional (1) in the sense that it requires economical movement. In fact, the founder of judo, Jigora Kano describes the excellent judo technique as one where efficiency and economical 
movement will lead to a successful throw. In being functional, sport has a formal, structural cohesion (2) that is expressed in the very "logic" of a series of movements. In science this is akin to the craft of the sciences and its methods of observation, analysis and inference.

What appeals to the observer and what needs to be at play in participating in most sports (read: sciences) is a certain composure - both bodily and in terms of mental focus. Thirdly, the tensions, the gravity, the inertia, the energy expressed by a sports movement, exemplifies physics in the form of action (3). Many sports somehow encapsulate in visually pleasing ways the potential of the body (mind) at the precipice of physical (and mental) possibility. We admire and praise how the sportsman (artist, scientist...) uses his/her craft to show us what can be achieved through his/her mastery of the sport (art. science...) within the confines of the limitation - temporarily overcome - of our embodiment. Lastly, there is a metaphysical aspect (4) in that the first three more physical attributes are all given impetus by human will. Will itself, in a kind of Schopenhauerian and Nietzschean sense, might be a more fundamental or metaphysical property "behind" the veil of nature and natural movement, giving one an intuitive sense of action that defies the ordinary, which might be particularly evident in sport (read: science) especially at the elite level.

The expression of will-power, of surmounting difficulties by performing optimally in sports-acts (or through art, science...) is simultaneously an expression of the spirit, hence we emotionally identify with the sportsmen and women (or artists or scientists for that matter) that express and ply their craft come what may. To unravel further what the sportsperson and artist may express other than simply the effort in expression itself. I concur with Guyer's claim that Kant's influence on architecture may be responsible for the idea that not only that it (architecture...) should express ideas, but specifically what those ideas should be. For example, in the case of the post-Kantian leading philosophers, such as Schelling, Schopenhauer and Hegel, one detects this Kantian influence. In the case of Schelling, Guyer (2011) argues that architecture, in order to be art, need not be concerned with utility as such, but as the expression of something intellectual. By this he may mean, in his words that: "...the most primal sequence is numbers...that architecture, as the music of the plastic arts, thus necessarily follows arithmetical relationships" (in Guyer 2011:11). Architecture should express or symbolize arithmetical relationships; that should be the architect's goal. Schopenhauer argued that, as Guyer (2011: 12) simplifies: "...that the work of architecture should express not their function, but rather the nature of their own construction and the physical forces involved in and affecting that construction".

With Hegel, architecture should express metaphysical ideas about divinity and spirit (here equated with reason) itself, but that this project is undermined as "art, considered in its highest vocation, is and remains for us a thing of the past" (in Guyer 2011:13). This account above serves to suggest that Kant influenced these philosophers in their move away from architecture as utility towards an expression of aesthetic ideas. Kant's attempt to explain what these ideas consist of, however, deconstruct in his own writing, as form and matter, that which suggests rich intellectual content, "cannot be reduced to any rule but instead triggers inexhaustible and pleasurable motion or free play in the mind of its audience" (in Guyer 2011:16). With this, the door is opened for an expansive theory and practice of art, and this applies to architecture as well. The implication for sport (read: science), if we are to maintain that it does express aesthetic ideas, is that an overarching discursive theory of sport is not forthcoming as its forms - the evolution of existing games and the creation of new games (read: sciences) - forever changes and grows exponentially. In this spirit, one might maintain that sport does express a kind of mathematical pattern according to Schelling; that sport does express the coming together of natural forces according to Schopenhauer and that the "death of art" posited by Hegel is itself a thing of the past, as art aesthetics does exist in spheres usually considered not aesthetic, such as sport and science. The shift from a Vitruvian conception of architecture to an expressive one may be read in postmodern terms as a shift from an aesthetic-technicist conception of sport to an aesthetic-expressive one in the Kantian sense.

\section{Conclusion}

I believe that an individual, emotive appeal is not only a primary motivation in art and sport (read: science), but also the by-product of a delight in sensual patternmaking and harmony. In this respect, one would do well not to simply recognize the emotional flavor of that delight, but the more cerebral, formal dimension of artistic and sports (read: science) play. At this point one could, however, say that "expression" which at the outset may appear to be riddled with modernist notions concerning individual agency and centrality, really becomes one in which aesthetic "play", (aesthetic) struggle and emotional satisfaction can apply equally well to a range of cultural domains, thus deconstructing the idea that "true" emotions are only reserved for "higher" culture.

An expressive account of human agency offers a reprieve from a social account of art and indeed, sport (read: science). In this respect, the expressive does not dismiss the significance of the self, without necessarily lapsing into asserting one aesthetic over and above another. The early formulation of the expressive theory of art outlined by Tolstoy and perhaps to a lesser extent by Collingwood, are natural links in a chain that leads to an aestheticization of the "everyday". Furthermore, the expansive interinclusion of a number of emotional states that bear when producing the aesthetic object mimics the range of emotions one might ascribe to "everyday" living as such and art, science and sport in particular. Guyer's application of Kant in the realm of architecture as an expression of ideas was read (interpreted) as applicable to the "everyday" life of sport because such "ideas" carry content made possible via self-expression. I further extended such a reading as applicable to science. This then shows or argues for an overlap between such variables as aesthetics; art; sport and science and such a "mixing" in defined as one instance of the New Paradigm, an inert-disciplinary paradigm shift wherein knowledge is perceived as unified, as one. Such a vision "allows" for deeper explanatory scope which perhaps amplifies the "observations" that such "relational thinking": may bring forth: an expression toward the ineffable and a unity of the mind and body. 


\section{A Qualifying Note:}

Notwithstanding, my argument regarding a unifying and connecting stratum - a New Paradigm - that suggests the "mixing" and interdisciplinary nature of all things and all modes of comprehension, this is not a totalizing and ultimate system of thought. For the "epistemological unity" is itself and necessarily predicated on difference, singularity, identity, separation, and divide.

Just as each person is an individual; each thing a thing; A is A and not not A or B and so on, so individuals, things, languages, branches of knowledge and words form a separate and not an inter-related dimension of being. Even though such entities are not simple and are composed of parts, nevertheless it is a singular, separate, and individual identity. In conclusion then, my argument entails a necessary dualism: on the one hand there is separation and divide, each entity being/language/discipline and so on unrelated to the next and a world in itself and each such entity forms part of a larger whole which in academia vacates a space for the so-named inter-disciplinary.

Thus, this note should be considered in conjunction with my project - at once seeking oneness and at the same time, the impossibility of such a task, that each "thing" is one and separate in itself, identical to itself and unlike any other "thing". In this respect, the vessel, the body is singular - an individual instantiation of the light - while the light itself pervades all things.

\section{References:}

[1].Collingwood, R. 1936. The principles of art. New York: Oxford University Press.

[2].Guyer, P. 1997. Kant and the claim of taste. Cambridge: Cambridge University Press.

[3].Guyer, P. 2011. Kant and the philosophy of architecture. The American Society for Aesthetics 34(2):7-19. [4] Hyland, DA. 1984. The question of play. Washington: University Press of America.

[4].Hyland, DA. 1990. Philosophy of sport. Maryland: University Press of America.

[5].Janson, F. 1967. History of art. New York: Prentice Hall.

[6].Kant, I. 1952 [1790]. The critique of judgment. Translated with analytical indexes by Meredith, J. New York: Clarendon.

[7].Osterhoudt, R (ed). 1973. The philosophy of sport. New York: Charles Thomas.

[8].Shusterman, R. 2008. Body consciousness: a philosophy of mindfulness and somaaesthetics. New York: Cambridge University Press.

[9].Tolstoy, L. 1898. What is art? London: The Brotherhood.

[10]. Weitemeier, H. 1995. Yves Klein. Berlin: Benedict Taschen.

[11]. Weiss, P. 1969. Sport: a philosophic inquiry. Illinois: South Illinois University Press.

[12]. Womack, M. 2003. Sport as symbol: images of the athlete in art. London: McFarlend \& Co. 